\title{
DiÁlogos entre A EDUCAÇÃo PATRIMONiAl E PAUlo Freire
}

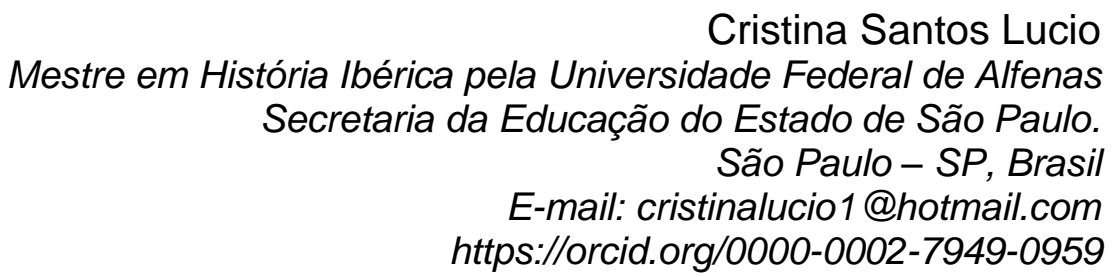

\section{RESUMO}

Este artigo visa abordar a Educação Patrimonial no Brasil tendo como base a análise de documentos produzidos pelo IPHAN (Instituto do Patrimônio Histórico e Artístico Nacional) e a revisão bibliográfica de estudos de pesquisadores sobre o tema enquanto metodologia, partindo da problematização da relação da educação patrimonial como prática de liberdade. Como resultado, foram apresentadas discussões de termos desenvolvidos por Paulo Freire para pensar uma educação patrimonial crítica, inclusiva e democrática em oposição a uma educação patrimonial conservadora.

PALAVRAS-CHAVE: Educação patrimonial; Paulo Freire; preservação; pluralismo cultural; patrimônio cultural. 


\section{ABSTRACT}

This paper aims to approach the Heritage Education in Brazil based on the analyses of documents produced by IPHAN (Institute of National Historical and Artistic Heritage) and the bibliographical review of studies from researchers about the subject as a methodology, stemmed from the problematization of the relation of heritage education as a practice of freedom. As a result, discussions of terms developed by Paulo Freire to think about a critical, inclusive and democratic heritage education as opposed to a conservative heritage education were presented.

KEYWORDS: Heritage Education; Paulo Freire; preservation; cultural pluralism; cultural heritage.

\section{RESUMEN}

Este artículo tiene como objetivo abordar la educación patrimonial en Brasil a partir del análisis de documentos producidos por IPHAN (Instituto del Patrimonio Histórico y Artístico Nacional) y la revisión bibliográfica de estudíos de investigadores acerca del tema como la metodología. Como resultado, se presentaron discusiones de términos desarrollados por Paulo Freire para pensar en una educación patrimonial crítica, inclusiva y democrática en contraposición a una educación patrimonial conservadora.

PALABRAS CLAVE: Educación patrimonial; Paulo Freire; preservación; pluralismo cultural; patrimonio cultural. 


\section{INTRODUÇÃO}

A Educação Patrimonial, apesar de ser um campo ainda não consolidado e em construção no Brasil (SCIFONI, 2015, p. 195), vem conquistando espaço nas discussões acadêmicas nas últimas décadas, bem como em outros ambientes que são espaços de formas de educação, como os museus, e, ainda que por vezes de maneira tímida, tem estado presente nos bancos escolares também. A educação para a preservação, baseia-se em princípios relacionados à democracia e cidadania, não sendo, portanto, neutra. Trata-se de uma educação política que deve dialogar com a pluralidade cultural (FLORÊNCIO, 2012, p.32) de maneira crítica.

Desta forma, é necessário enfatizar que a abordagem e os recortes feitos dentro da educação patrimonial são cruciais para uma educação inclusiva e significativa, e que sem a criticidade, esta prática pedagógica pode ser um mecanismo de manutenção de estruturas, de maneira conservadora. Assim, o objetivo será apresentar estudiosos do tema e obras de Paulo Freire a fim de analisar a educação patrimonial fora das fronteiras da educação patrimonial conservadora. Esta vertente é definida como uniformizante e homogeneizante por partir de uma forma de memória e de identidade que prioriza os detentores do saber sistematizado, oficial e integralizante ao não possibilitar a identificação de outros espaços e manifestações (MAGALHÃES, ZANON, BRANCO, 2009, p.55).

Esta abordagem está arraigada ao contexto em que foi desenvolvida quando o próprio conceito de patrimônio estava intimamente ligado à uma memória nacional que vislumbrava patrimônios remetentes às elites e aos grandes cenários, explicitando - muitas vezes de maneira arbitrária - determinados recortes acerca do que eram considerados patrimônios, logo, não possibilitando a multiplicidade de memórias. Ademais, o foco deste tipo de visão de educação patrimonial foca a preservação pela preservação, sem se preocupar com a compreensão e apropriação dos patrimônios. Neste sentido, a justificativa para a realização deste artigo é a necessidade de reiterar a educação como prática política de liberdade em oposição a uma educação patrimonial esvaziada de sentido e antidialógica.

O artigo está dividido entre introdução, duas seções e considerações finais. Em Breve síntese sobre a educação patrimonial no Brasil, foram analisados sobretudo o Guia Básico da Educação Patrimonial pelo Instituto do Patrimônio Histórico e Artístico Nacional - Museu Imperial (1999), de autoria de Maria de Lourdes Parreiras Horta, Evelina Grunberg e Adriane Queiroz Monteiro e o dossiê Educação Patrimonial: Histórico, conceitos e processos (2014), tendo como autores Sônia Rampim Florêncio, Pedro Clerot, Juliana Bezerra e Rodrigo Ramassote. Na segunda seção, intitulada $A$ educação patrimonial aos olhares de pesquisadores brasileiros, foi feita uma revisão bibliográfica sobre capítulos e artigos de Pedro Paulo Abreu Funari, Raquel dos Santos Funari, Ricardo Oriá Fernandes, Circe Bittencourt, Sônia Regina Rampim Florêncio, Simone 
Scifoni, Janice Gonçalves, Márcia Bezerra, Flávio Leonel Abreu da Silveira, Elisa Roberta Zanon, Leandro Henrique Magalhães, Patrícia Martins Castelo Branco, Jackson Schwengber, Diego Scherer da Silva e Rhuan Zaleski Trindade sobre educação patrimonial. O ponto de congruência são os termos freirianos aplicados para pensar uma educação patrimonial para a liberdade.

\section{BREVE SÍNTESE SOBRE A EDUCAÇÃO PATRIMONIAL NO BRASIL}

A preocupação com a importância do que seria conhecido como Educação Patrimonial já era sentida desde a criação do IPHAN (Instituto do Patrimônio Histórico e Artístico Nacional) por via de documentos e publicações. Um dos responsáveis por esses apontamentos foi o poeta Mário de Andrade ainda em 1930, na época o SPHAN (Serviço do Patrimônio Artístico Nacional). ${ }^{1}$

Andrade realçava veementemente a importância do caráter pedagógico presente em museus e do potencial educativo presente em imagens. Rodrigo Melo Franco de Andrade, diretor do Instituto durante 30 anos, estando presente desde a fundação do que conhecemos hoje por IPHAN, caminhava pela mesma linha ideológica de Mário de Andrade, chegando a defender a posição de quão significativa era a relação entre a educação e a preservação do patrimônio cultural brasileiro em alguns artigos e discursos (FLORÊNCIO, 2012, p.22). Apesar desse breve histórico, é no final da década de 1970 que essa ideia passa a ser abordada de forma mais incisiva sob a orientação de Aloísio Magalhães. Nessa visão, as comunidades passaram a ser vistas para além de meros objetos de estudo, mas como sujeitos apontando a imagem da comunidade como "guardiã" do patrimônio. Na década de 80, é cunhada a expressão "Educação Patrimonial" como um reflexo das experiências educacionais ocorridas na Inglaterra, o Heritage Education, onde museus e monumentos históricos passaram a ser utilizados com fins educacionais (FLORÊNCIO, 2012, p.23).

Oficialmente, essa introdução da Educação Patrimonial ocorreu no $1^{\circ}$ Seminário sobre o Uso Educacional de Museus e Monumentos realizado em julho de 1983, ocorrido no Museu Imperial (Petrópolis-RJ). De acordo com Horta, Grunberg e Monteiro (1999), a partir deste seminário foram propostas e realizadas atividades aplicadas pela mencionada metodologia em diferentes contextos

\footnotetext{
1 Em janeiro de 1937 foi reorganizado o Ministério da Educação sob o comando de Gustavo Capanema, e criado o Serviço de Patrimônio Histórico e Artístico Nacional (SPHAN). Com o SPHAN em vigor, iniciou-se uma série de ações para a realização da identificação, catalogação, restauração, conservação, preservação, fiscalização e difusão dos patrimônios de interesse do Estado nos anos vindouros. Para que chegasse à nomenclatura atual IPHAN, décadas de atividades e modificações foram realizadas no que concerne aos patrimônios e suas políticas públicas. Essas modificações, feitas ao longo de diversos contextos históricos do país, afetaram não somente 0 andamento de trâmites relacionados a processos de salvaguarda, como também a própria denominação da instituição, passando de SPHAN para Diretoria do Patrimônio Artístico e Nacional (DSPHAN) em 1946, e, finalmente, para IPHAN em 1970 (THOMPSON, TEIXEIRA, REZENDE, GRIECO, 2015).
} 
e locais do Brasil que tiveram resultados positivos no que tange à "recuperação da memória coletiva, resgate da autoestima de comunidades em processo de desestruturação, no desenvolvimento local e no encontro de soluções inovadoras de preservação do patrimônio cultural" (HORTA; GRUNBERG; MONTEIRO, 1999, p. 1).

No fim do século passado, mais especificamente em 1999, Maria de Lourdes Parreiras Horta publicaria junto a Evelina Grunberg e Adriane Queiroz Monteiro um documento chamado Guia Básico da Educação Patrimonial pelo Instituto do Patrimônio Histórico e Artístico Nacional - Museu Imperial. Este documento, considerado um importante norteador da Educação Patrimonial no Brasil, busca trazer o assunto à tona do cotidiano de professores, anexando inclusive modelos de atividades que podem ser desenvolvidas, bem como pontos caros e intimamente relacionados ao tema discutido, como o próprio patrimônio cultural, a noção temporal de passado e presente e de fontes passivas de serem vistas enquanto patrimônios, buscando trazer uma metodologia sobre essa vertente, conforme defendem as autoras.

Neste documento oficial, a Educação Patrimonial é definida como um "processo permanente e sistemático de trabalho educacional centrado no Patrimônio Cultural como fonte primária de conhecimento e enriquecimento individual e coletivo". As autoras seguem afirmando que, neste sentido, se trata de "tomar objetos e expressões do patrimônio cultural, questionando-os e explorando seus diferentes aspectos que podem ser traduzidos em conceitos e conhecimentos na prática escolar", tomando-os como indícios para a investigação (HORTA; GRUNBERG; MONTEIRO, 1999, p.1).

A segunda etapa deste processo seria recorrer ao que as autoras chamam de "fontes secundárias", que podem ser compreendidas como livros e textos que terão a função de ampliar o conhecimento sobre os patrimônios. Desse modo, a Educação Patrimonial teria por objetivo levar a crianças e adultos o conhecimento, apropriação e valorização de sua herança cultural. Esse processo teria a finalidade de capacitar os indivíduos para um melhor usufruto desses patrimônios. O conhecimento crítico e a apropriação consciente dos bens são fatores citados no documento como indispensáveis para que a preservação desses bens ocorra juntamente ao sentimento de cidadania e identidade (HORTA; GRUNBERG; MONTEIRO, 1999, p.2).

Junto a estes princípios, a diversidade da herança cultural brasileira trazida através de patrimônios para as aulas, auxiliaria a formação do sentimento de tolerância, valorização e respeito às diferenças. É ressaltado também, que tomando esse ponto, contribuiria para criticar o pensamento de hierarquias culturais, rompendo com a leitura de que determinada sociedade possui mais cultura do que a outra, como se existissem culturas inferiores e superiores ${ }^{2}$. Há ainda outra

2 Quando é mencionado o termo "cultura" neste contexto, é invocado o sentido imperante no século XIX. A cultura oitocentista refere-se ao sentido alemão kultur, em que a cultura era usualmente dividida em dois 
face explorada pelas autoras do documento: o princípio de que o diálogo entre esses assuntos no processo educacional estimula e facilita a relação e comunicação entre os grupos responsáveis pela salvaguarda, preservação e estudo dos bens culturais com as comunidades, abrindo possibilidade de troca de conhecimentos entre esses dois segmentos, bem como de formação de parcerias tendo como fim a proteção desses patrimônios (HORTA; GRUNBERG; MONTEIRO, 1999, p.2).

Dentro desses parâmetros, as autoras assinalam que a Educação Patrimonial pode ser vista como um instrumento de alfabetização cultural amparadas no conceito teórico de empoderamento de Paulo Freire, onde há reforço e capacitação para o exercício da autoafirmação. Esse processo ocorreria mediante a ideia de possibilitar ao indivíduo "fazer a leitura do mundo que o rodeia, levando-o a compreensão do universo sociocultural e da trajetória histórico-temporal em que está inserido" (HORTA; GRUNBERG; MONTEIRO, 1999, p.2-3).

No dossiê Educação Patrimonial: Histórico, conceitos e processos, produzido em 2014 (IPHAN), a Educação Patrimonial é entendida como uma prática que pode estar presente tanto nos processos educativos formais quanto nos processos não formais, desde que tenham como foco o "patrimônio cultural, apropriado socialmente como recurso para a compreensão sócio-histórica das referências culturais em todas as suas manifestações, a fim de colaborar para seu reconhecimento, sua valorização e preservação" (FLORÊNCIO et al, 2014, p.19). No documento, é afirmado que se deve primar para que os processos educativos relacionados ao Patrimônio Cultural sejam construídos de maneira coletiva e democrática a partir do diálogo entre comunidade e agentes culturais e sociais, levando em consideração as diferentes visões presentes sobre o Patrimônio Cultural.

A política de Educação Patrimonial do IPHAN está estruturada em três eixos de atuação: inserção do tema Patrimônio Cultural na educação formal (tanto na educação básica como na superior), gestão compartilhada das ações educativas (um dos pontos latentes nesse ponto são as Casas do Patrimônio) e a instituição de marcos programáticos no campo da Educação Patrimonial. De acordo com o dossiê do IPHAN, "essas diretrizes foram consolidadas nos seguintes documentos: Carta de Nova Olinda (2009), I Fórum Nacional do Patrimônio Cultural (2009) e Documento do II Encontro Nacional de Educação Patrimonial” (2011) (FLORÊNCIO et al, 2014, p.29).

extremos: a cultura erudita, esta, reservada aos ditos "civilizados"; e, do outro lado da dicotomia, a cultura dos "bárbaros", a "baixa cultura" (PELEGRINI; FUNARI, 2006, p.24). 


\section{A EDUCAÇÃO PATRIMONIAL AOS OLHARES DE PESQUISADORES BRASILEIROS}

Agora, trabalharemos com outros autores que versam sobre o conceito da Educação Patrimonial. Segundo Raquel dos Santos Funari e Pedro Paulo Abreu Funari (2008, p.11), a Educação Patrimonial possui a característica de ser interdisciplinar e transdisciplinar, pois apesar de o patrimônio estar intimamente envolvido com a História, ele dialoga também com a Arqueologia, as Artes (os autores enfatizam, neste ponto, a Arquitetura), a Geografia, a Linguagem e até mesmo a Matemática.

Para Ricardo Oriá Fernandes (1995, p.142), em consonância com Horta, Grunberg e Monteiro (1999), a Educação Patrimonial está ligada a questões do Patrimônio Cultural onde temáticas ou conteúdos programáticos devem versar sobre o conhecimento e a conservação do patrimônio histórico, reiterando o empowerment ${ }^{3}$ proposto por Paulo Freire. O autor defende que para tanto é necessário a inclusão dessa vertente em currículos de todos os níveis de ensino, bem como deve haver a capacitação através de cursos para educadores e comunidade em geral dentro da aprendizagem significativa, para que possam ser habilitados a criar bases para que os educandos possam construir o senso de preservação dessas heranças.

Neste aspecto, Circe Bittencourt (2004, p. 278) enfatiza a importância das políticas de preservação patrimonial. A autora defende uma Educação Patrimonial para as atuais e futuras gerações tendo como ponto central o pluralismo cultural, alicerçada na concepção de uma educação que não vise apenas aos grandes monumentos históricos como também olhe para a rememoração e preservação acerca do que é considerado importante para a comunidade local. A autora afirma que a salvaguarda do patrimônio deve estar pautada no compromisso de contribuição com a identidade cultural dos diferentes grupos integrantes da sociedade.

Bittencourt segue analisando o motivo pelo qual é relevante o critério de escolha dos patrimônios a serem trabalhados nas aulas. Como mencionado acima, se forem escolhidos somente edifícios e outros patrimônios com referência à notabilidade histórica, por assim dizer, pode-se levar os alunos a uma ideia de História dos dominantes, afirmando que o que é importante esteja concomitantemente relacionado com aqueles que fizeram e escreveram a História em tempos passados, legitimando um tipo de pensamento que sustenta as tradicionais relações de poder. Sobre essa escolha de patrimônio, Circe Bittencourt (2004, p.279) cita o historiador e pesquisador da educação francês Jean-Noël Luc que afirma que todo meio, rural ou urbano, está situado no tempo. Logo, possui história que deixou marcas registradas em si mesmo e no seu entorno, indícios

\footnotetext{
${ }^{3}$ Empowerment, o empoderamento, é compreendido por Paulo Freire como o empoderamento de classe social, processo esse caracterizado por não ser individual. Freire afirma não acreditar na autolibertação, já que percebe a libertação como um ato social (FREIRE; SHOR, 1986).
}

| (C) Rev. Arqueologia Pública | Campinas, SP | v.17 | n.02 | p.110 | 12/2021 |ISSN 2237-8294 
esses que testemunharam existências anteriores, ligando o passado e o presente. Bittencourt classifica que o pensamento de que "todo meio é histórico" representa noção fundamental para os professores de História que podem ser determinantes na escolha dos espaços a serem estudados.

A grande questão, portanto, está nas perguntas feitas aos monumentos, independentemente de sua natureza ou contexto, está em direcionar o olhar do aluno, entendendo o patrimônio enquanto um tipo de fonte histórica que muito tem a nos dizer. Exemplos destacados por Bittencourt são as construções dos telhados das casas, o planejamento urbano, as plantações, os instrumentos de trabalho, as informações obtidas pela memória oral das pessoas comuns. A autora sintetiza que as fontes históricas são marcas do passado que se transformaram em material de estudo (BITTENCOURT, 2004, p.280). Em congruência, Pedro Paulo Abreu Funari e Raquel dos Santos Funari (2008, p. 7) afirmam que:

"Educação Patrimonial é uma metodologia que busca a valorização dos bens culturais a partir das manifestações materiais (...) desenvolvida junto aos diferentes grupos formadores da sociedade, viabiliza a formação de identidades, aumento da autoestima e posterior valorização dos bens materiais."

Florêncio (2012) defende a Educação Patrimonial enquanto um conceito basilar da valorização da diversidade cultural, pois, essa seria uma forma de fortalecer as múltiplas identidades e alteridades, reafirmando as diferentes maneiras de ser e estar no mundo. A autora segue afirmando esse fortalecimento de questões identitárias como um modo de evidenciar a visibilidade de culturas marginalizadas ou excluídas, facetas fundamentais para os diálogos interculturais, bem como sedimentar o compromisso da cultura de tolerância à diversidade.

Sônia Regina Rampim Florêncio converge com Circe Bittencourt (2004) e Ricardo Oriá (1995) no que diz respeito à forma como as políticas públicas se alinham com o patrimônio cultural e na articulação de saberes diferenciados e diversificados, destacando as disciplinas nos currículos na educação formal (FLORÊNCIO, 2012, p.23-24). Ainda em relação às políticas públicas, Florêncio as estende ainda ao vínculo das mesmas ao "turismo cultural, meio ambiente, educação, saúde, desenvolvimento urbano e outras áreas correlatas, favorecendo, então, o intercâmbio de ferramentas educativas de modo a enriquecer o processo pedagógico inerente a elas" (FLORÊNCIO, 2012, p.26).

Simone Scifoni, em seu artigo Para repensar a Educação Patrimonial (2015), tece críticas à ideia hegemônica que se tem de Educação Patrimonial e aponta questões que em sua análise devem ser repensadas, fazendo jus ao título do seu texto. Scifoni inicia criticando o fato de a Educação Patrimonial ainda não ter alcançado raízes em nosso país, atribuindo a primeira problemática à própria origem do termo que foi firmado, regressando ao conceito originalmente 
importado da língua inglesa. A autora segue indicando ainda o já mencionado Guia Básico de Educação Patrimonial (1999) que, aos olhos de Simone Scifoni, seria um dos responsáveis pela consolidação do conceito conhecido até hoje no Brasil (SCIFONI, 2015, p.195). Scifoni (2012, p. 31) aponta ainda que a carência de reflexão teórica sobre a Educação Patrimonial está atrelada, ainda que em parte, com o que ela denomina "dificuldades de ordem prática e estrutural" no que tange a insuficiência de recursos humanos e materiais para a execução de projetos, salientando também a falta de formação na área.

Ao fim e ao cabo, a grande crítica gira em torno da utilização da Educação Patrimonial sem criticidade. A autora defende que haja a reflexão sobre o tipo de herança que está sendo abordada e o que se quer trazer para os alunos com essa transmissão, atentando-se que valores são historicamente construídos. Assim como Horta, Grunberg e Monteiro (1999), Scifoni busca em Paulo Freire (2001) os princípios para uma nova pedagogia do patrimônio através da educação como prática de libertação (SCIFONI, 2015, p.203).

Neste sentido, é possível tecer uma relação entre a educação patrimonial e a cultura material se pensarmos que as leituras de ambas estão concatenadas a discursos do tempo em que são interpretadas ou, no caso da educação, produzidas. Outro ponto de congruência, é que não há neutralidade tanto na cultura material quando na educação patrimonial.

Ao criticar a educação patrimonial conservadora enquanto uma estrutura que pode legitimar determinados recortes arbitrários do passado ou da memória, é possível considerar também que a cultura material pode fomentar identidades a partir das interpretações de arqueólogos. Renata Senna Garraffoni (2013, p.223) reitera que a análise dos investigadores da cultura material não escapa das discussões políticas vigentes no tempo presente destes profissionais, e que logo, é necessário ponderar que a cultura material já pode ter sido empregada para vários usos do passado e que pode ser entendida como base para discursos, fazendo-se necessário ao arqueólogo conhecer não só o contexto histórico em que a cultura material analisada foi produzida como também as relações de poder do tempo presente (2013, p.224).

A educação emancipadora seria uma alternativa para a ausência de crítica na Educação Patrimonial. Levando em consideração que não há neutralidade na escolha dos patrimônios, é necessário sempre salientar que memória e preservação são integrantes de relações de poder, já que patrimônios podem ser legitimadores destas estruturas. Existem algumas perguntas que sempre devem integrar o repertório daquele (s) que se aventurem a estudar patrimônios: por que se tornou patrimônio? Para quem? Quem escolhe o que preservar ou não? Como essas escolhas são feitas? A quais memórias elas atendem? Scifoni conclui que se perguntas como essas não 
forem pensadas, somente haverá a contribuição para a fetichização do patrimônio, tornando-o um modo de reprodução das relações de dominação (SCIFONI, 2015, p.203 - 204). ${ }^{4}$

Esta visão de educação inclui as comunidades como sujeitos do processo. Assim, firma-se outra visão acerca dos lugares (e, porque não, das manifestações), erigida a partir de um diálogo entre as comunidades e os agentes de instituições, não um monólogo. Desse modo, se ouve e constrói em conjunto entre os conhecimentos técnico-científicos produzidos nos órgãos de preservação e os populares e locais.

Tanto Janice Gonçalves (2017) quanto Márcia Bezerra e Flávio Leonel Abreu da Silveira (2007) tecem a mesma crítica ao assunto: as problemáticas inerentes no discurso de "conscientizar o outro". Bezerra e Silveira afirmam que:

“(...) a ideia redentora de conscientizar o Outro, tão propalada por educadores e técnicos do campo do patrimônio, revela uma violência simbólica (BOURDIEU, 1989) ante as comunidades, visto que se apresenta pouco afeita ao olhar antropológico que toma o Outro como um sujeito capaz de realizar a sua própria hermenêutica do mundo no qual está inserido" (BEZERRA; SILVEIRA, 2007, p.87).

Os autores tomam o conceito de Bourdieu de violência simbólica no que concerne em sua análise à relação entre os sujeitos que "receberão as informações e conhecimentos" e aqueles que são responsáveis pela "conscientização", onde os que estarão na posição de aprender sobre o patrimônio passem a pensar segundo as categorias mentais herdadas dos incumbidos por levar essa conscientização. Na crítica dos autores, projetos de Educação Patrimonial acríticos com perspectivas conscientizadoras não dariam a real consideração ao prisma dos envolvidos com o processo de conservação patrimonial, tomando-os como pessoas que precisam ser iluminadas pelo conhecimento, não como integrantes do processo. Bezerra e Silveira apontam que essa perspectiva deve ser substituída pela sensibilização, inclusão e participação desses sujeitos na Educação Patrimonial (BEZERRA; SILVEIRA, 2007, p.88). Atrelada às afirmações de Bezerra e Silveira, Scifoni (2012, p.32-33) cita o termo invasão cultural de Paulo Freire. A invasão ocorreria quando aqueles que deveriam ser os principais protagonistas são vistos como receptores de informações e conteúdos e não são envolvidos nos projetos.

É importante, entretanto, avaliar que o termo "conscientizar" empregado aqui não é o mesmo que o entendido por Paulo Freire. A conscientização, segundo Freire (1979) é compreendida como a emancipação do homem de sua figura reificada através da transformação de sua realidade se

\footnotetext{
${ }^{4}$ A autora define fetichização do patrimônio como vê-lo como a coisa em si mesmo, autônomo e independente dos processos que o construíram, servindo a propósitos de ocultar os sujeitos do trabalho e também as relações conflituosas e de dominação que envolvem a sua produção, tornando-o um objeto aparentemente neutro. A autora propõe que é preciso compreender o patrimônio à luz dos processos sociais que o produziram e dos quais ele é testemunha (SCIFONI, 2012, p. 36).
} 
construindo como sujeito da História. Scifoni aponta que a perspectiva conscientizadora de Freire pode ser empregada na Educação Patrimonial com a "mediação da cultura e das práticas educativas da cultura e patrimônio", sendo "possível contribuir para a tomada de consciência dos homens como sujeitos da sua própria história". Ademais, Simone Scifoni declara que com essa definição de "tomada de consciência", Paulo Freire não interpela uma possível tomada de consciência em relação à cultura, como se esta tivesse que ser conquistada por não ser inerente ao indivíduo, mas sim entender a cultura como mediação entre os indivíduos e sua consciência de si mesmo e de sua ação (SCIFONI, 2012, p.33).

Podemos concatenar com este ponto a afirmação de Simone Scifoni (2015, p.204) sobre a importância da educação problematizadora. Esse viés é descrito como o processo onde as pessoas são incluídas e compreendidas como sujeitos que se percebem criticamente no mundo e a consciência sobre sua própria história. Janice Gonçalves (2017) entende que a ideia de "defesa" do patrimônio seguindo a perspectiva da inculcação tende a empobrecer a ação educativa, e que a formação para a autonomia e afirmação do pensamento crítico são caminhos para escapar da visão de uma Educação Patrimonial excludente, ou como Magalhães, Zanon e Branco (2009) nomearam: Educação Patrimonial Conservadora.

A Educação Patrimonial Conservadora é descrita como universalizante e homogeneizante quando imposta de cima para baixo pressupondo uma identidade e uma memória, integralizante quando não há abertura para identificação de outros espaços e manifestações, portanto, vinculada aos interesses de grupos dominantes seguindo a tendência de rejeição às tradições ou valores destoantes da memória oficial que se pretende enfatizar, mantém o foco somente na preservação e não na apropriação e interpretação feitas pelos indivíduos (MAGALHÃES, ZANON, BRANCO 2009, p.55).

Os autores abordam a grande diversidade presente no Brasil, tanto social, cultural quanto étnica, que pressupõe visões pluralizadas sobre os patrimônios e afirmam que a Educação Patrimonial Conservadora não deve caber a partir da imposição de uma perspectiva única e elitista, a serviço das classes dominantes. Neste ponto, é ressaltado que o princípio da educação patrimonial dever estar ligado aos interesses da população (MAGALHÃES, ZANON, BRANCO, 2009, p.57), reiterando que aos patrimônios que dizem respeito sobre as classes mais abastadas recebam outros olhares analíticos e indagações.

Por fim, há outra crítica movida por Simone Scifoni (2015). Para compreendermos a crítica da autora, deveremos retomar o ponto da educação patrimonial como mantedora de estruturas, acrítica (ponto esse, inclusive, convergente entre outros autores mencionados, como Bittencourt (2004), Janice Gonçalves (2017), Márcia Bezerra e Flávio Leonel Abreu da Silveira (2007)). Scifoni analisa a nomenclatura Educação Patrimonial de maneira incisiva no que diz respeito à subtração 
da concepção de Educação em detrimento das questões do universo da cultura, como se a discussão acerca de educação em si já estivesse sido resolvida, se o debate fosse dispensável ou ainda se fosse um campo neutro. A autora afirma que: (...) "a Educação não é neutra, ao contrário, é o campo privilegiado do enfrentamento político-ideológico" (2015, p. 32).

Mais uma vez, Scifoni (2015) retoma Paulo Freire ${ }^{5}$ e volta a utilizar termos freirianos para explicar por meio destes o tipo de Educação Patrimonial que se pretende desenvolver. Freire teorizou que semelhantes sentidos conflitantes estão por trás da chamada ação cultural, onde ou ela está configurada para estar a mando do mantimento da estrutura social de dominação, com o objetivo de mistificar o mundo segundo a postura dominada ação cultural antidialógica, ou assume o porte de uma educação emancipadora, a ação cultural dialógica. O posicionamento entre estes dois caminhos determina a forma como as ações educativas serão estruturadas, dessa forma, sem princípios norteadores bem definidos, a Educação Patrimonial pode se tornar uma prática esvaziada de sentido. Ao não haver posicionamento, a autora afirma que existe o risco de propiciar ações incoerentes que até podem pretender ser dialógicas, mas que apenas reforçam os mecanismos de dominação (SCIFONI, 2015, p.32).

Neste ponto, vale retomar outro conceito freiriano, a educação bancária, entendida por Paulo Freire como o "saber" enquanto uma doação dos que se julgam sábios aos que nada sabem, cuja doação é fundamentada nas manifestações culturais da ideologia da opressão, destacada como a absolutização da ignorância, que constitui a alienação da ignorância, característica essa sempre encontrada no Outro (FREIRE, 1987). Daí Florêncio (2012, p.26) destaca a importância de uma educação mediadora para a construção coletiva do conhecimento, que vê a comunidade como produtora de saberes, reconhecendo, dessa forma, os saberes locais e a inserção dos bens culturais "em contextos de significados próprios associados à memória do local".

Em uníssono com Scifoni (2015), Florêncio (2012, p.24) ressalta o caráter político da Educação Patrimonial, realçando que as memórias e esquecimentos são produtos sociais, bem como os patrimônios. Os autores Elisa Roberta Zanon, Leandro Henrique Magalhães e Patrícia Martins Castelo Branco, em congruência com Scifoni e Florêncio, afirmam em Educação Patrimonial: da teoria à prática (2009, p.60) que a preservação e representação dos patrimônios estão vinculadas a interesses de grupos, pensando o patrimônio como um tipo de campo de disputa, pressupondo a existência de um duplo caminho. No Brasil, por exemplo, a instituição máxima na regência de patrimônios é o IPHAN (Instituto do Patrimônio Histórico e Artístico Nacional), que para

\footnotetext{
${ }^{5}$ FREIRE, Paulo. Pedagogia da autonomia: saberes necessários à prática educativa / Paulo Freire. - São Paulo: Paz e Terra, 1996. - (Coleção Leitura). Disponível em: https://nepegeo.paginas.ufsc.br/files/2018/11/Pedagogia-da-Autonomia-Paulo-Freire.pdf. Acesso em 21 nov. 2021. 
tombar e registrar patrimônios materiais e imateriais faz uso de parâmetros que denotam diversos elementos, como o de relevância, continuidade histórica e diversidade cultural (SCHWENGBER; SILVA; TRINDADE, 2012, p.467).

Silveira e Bezerra (2007) abordam duas perspectivas muito interessantes para refletir o patrimônio, ressaltando um conceito concernente ao tema: as paisagens patrimoniais. $O$ primeiro ponto é apoiado em Halbwachs (A memória coletiva, 1990), onde é tratada a relevância da relação entre paisagens patrimoniais e a memória coletiva, estas, "associadas a determinadas lembranças de caráter histórico-social" (BEZERRA; SILVEIRA, 2007, p.91).

O segundo ponto é a apresentação da perspectiva da polissemia da compreensão acerca do próprio termo "patrimônio", que de acordo com os autores, podem ser interpretados de diferentes formas por sociedades distintas. Para ilustrar essa afirmação, Bezerra e Silveira citam o trabalho desenvolvido por Fordred-Green, Neves e Green', onde "a partir de um projeto de Arqueologia Pública com grupos indígenas, observaram que os Palikur experienciam o passado não pelo patrimônio arqueológico, mas por narrativas inscritas na paisagem" (BEZERRA; SILVEIRA, 2007, p.90). Este excerto parece muito caro à análise de patrimônios, uma vez que sugere a abrangência da compreensão desse termo, guiadas pela forma que as diferentes sociedades sentem e enxergam seus bens culturais.

O debate sobre patrimônio é muito frutífero e amplo. Deve-se pontuar, no entanto, que o significado de patrimônio foi mutável ao longo dos diferentes contextos históricos em que foi empregado. Pode-se mencionar, por exemplo, a ideia ligada ao pater famílias da antiguidade, ao caráter das peças únicas presentes nos gabinetes de curiosidades e aos usos feitos de patrimônios na legitimação e formação dos estados nacionais, isso para citar algumas situações gerais. Se focarmos no Brasil, esse conceito foi sendo modificado, "iniciado com os modernistas nos anos 1930, com a valorização da herança colonial portuguesa, até a atualidade, com a política da diversidade cultural", pensando as heranças africanas e indígenas (SCHWENGBER; SILVA; TRINDADE, 2012, p.467). Neste sentido, cabe a citação abaixo, onde Funari e Pelegrini apresentam que com a ampliação do entendimento acerca do que se considerava patrimônio na segunda metade do século passado, ampliou-se também a diversidade de patrimônios e a vicissitude da valorização e salvaguarda destes bens:

"Com o despertar para a importância da diversidade, já não fazia sentido valorizar apenas, e de forma isolada, o mais belo, o mais precioso ou o mais raro. Ao contrário, a noção de preservação passava a incorporar um conjunto de bens que se repetem, que são, em certo sentido, comuns, mas sem os quais não poderia existir o excepcional" (FUNARI; PELEGRINI, 2006, p. 24)

${ }^{6}$ FORDRED-GREEN, L.; NEVES, E. G.; GREEN, D. "Arqueologia Pública na área indígena Uaçã, Amapá: problemas e perspectivas". In: Resumos - Congresso da SAB. Rio de Janeiro, 11, 2001. 
No mesmo horizonte, cabe a citação do que é entendido por patrimônio segundo a Constituição Federal Brasileira:

\begin{abstract}
"Art. 216. Constituem patrimônio cultural brasileiro os bens de natureza material e imaterial, tomados individualmente ou em conjunto, portadores de referência à identidade, à ação, à memória dos diferentes grupos formadores da sociedade brasileira, nos quais se incluem: I - as formas de expressão; II - os modos de criar, fazer e viver; III - as criações científicas, artísticas e tecnológicas; IV - as obras, objetos, documentos, edificações e demais espaços destinados às manifestações artístico-culturais; V - os conjuntos urbanos e sítios de valor histórico, paisagístico, artístico, arqueológico, paleontológico, ecológico e científico" (BRASIL, 1988).
\end{abstract}

Após essa brevíssima rememoração acerca dos diferentes patrimônios, cabe colocar o papel decisivo da Educação Patrimonial no processo de valorização e preservação dos bens culturais. Florêncio afirma que a promoção e a difusão dos conhecimentos técnicos não são suficientes, é necessário que sejam construídas relações efetivas com as comunidades, entendidas pela autora como protagonistas (FLORÊNCIO, 2012, p.24). É possível ligar a este ponto ainda a fala de Janice Gonçalves, que vê a Educação Patrimonial como um meio para a promoção do exercício da cidadania através da construção de práticas educativas, positivamente educativas (GONÇALVES, 2017, p.40).

\title{
CONSIDERAÇÕES FINAIS
}

Ao longo deste artigo, foi tratado o tema da educação patrimonial no Brasil. No início, foi abordado sucintamente como a educação patrimonial no Brasil foi pensada no começo de sua jornada sob a influência de Mário de Andrade e Rodrigo Melo Franco de Andrade na década de 1930, ao afirmarem o museu enquanto um espaço pedagógico e a importância dos patrimônios culturais. Nas décadas de 1970, 1980 e 1990, a educação patrimonial foi reiterada a partir da produção de documentos por instituições como o IPHAN (Instituto do Patrimônio Histórico e Artístico Nacional), desenvolvidos por estudiosos do tema, que sedimentaram e nortearam a educação patrimonial. Além disso, é na década de 80 que o termo educação patrimonial foi cunhado, com base no termo inglês Heritage Education.

No documento produzido em 2014 pelo IPHAN (Educação Patrimonial: Histórico, conceitos e processos), é reforçada a ideia de que a educação patrimonial é uma prática que pode estar presente tanto nos âmbitos da educação formal quanto na não formal, desde que o patrimônio cultural seja visto sob a perspectiva de ser um recurso para a compreensão sócio-histórica por meio do reconhecimento, preservação e valorização. Outra característica crucial destacada no 
documento é o princípio de que os processos educativos sejam construídos coletiva e democraticamente por meio do diálogo entre todas as partes envolvidas (comunidade, agentes culturais e sociais).

Assim, chegamos à crítica em voga tecida por estudiosos embasadas em termos freirianos: pensar e produzir uma educação patrimonial crítica que sensibilize e que seja construída de maneira dialógica, caracterizando a educação patrimonial como prática da libertação contrapondo a educação patrimonial conservadora. Esta última é caracterizada como uma abordagem acrítica e mantedora de determinadas estruturas de poder, focada na preservação pela preservação, e não na compreensão e apropriação dos patrimônios pela comunidade. Este tipo de perspectiva pode perpetuar a reprodução das relações de dominação.

Isto posto, deve-se partir do princípio de que esta prática pedagógica deva estar relacionada aos interesses da população, uma vez que também seja um campo político, o que exclui qualquer possibilidade de haver neutralidade na abordagem da educação patrimonial, tampouco na escolha do que são considerados patrimônios culturais. Neste sentido, deve-se atentar que estas escolhas ligadas a determinados recortes de memória (s) estão concatenadas às relações de poder, logo, são políticas. Por fim, são apresentadas definições de patrimônios e a importância da construção dessas políticas ligadas a educação patrimonial em conjunto com a população, longe de ser somente um monólogo excludente e homogeneizante, mas uma educação crítica e significativa.

\section{REFERÊNCIAS BIBLIOGRÁFICAS}

BITTENCOURT, Circe Maria Fernandes. Identidade nacional e ensino de história do Brasil. In: KARNAL, Leandro. (Org.). História na sala de aula. 1. ed. São Paulo: Contexto, 2004, p. 185204.

BRASIL. Constituição (1988). Constituição da República Federativa do Brasil. Brasília, DF: Senado Federal: Centro Gráfico, 1988.

FERNANDES, José Ricardo Oriá. Memória e ensino de história. In: Circe Maria Fernandes Bittencourt. (Org.). O saber histórico na sala de aula. 2. ed. São Paulo, SP: Contexto, 1995, v. 1, p.128-148.

FLORÊNCIO, Sônia Regina Rampim. Educação Patrimonial: um processo de mediação. In: Átila Bezerra Tolentino (Org.). Educação Patrimonial: um processo de mediação. 1.ed. João Pessoa PB, 2012. v. 2, p. 22-29.

FLORÊNCIO, Sônia Regina Rampim; CLEROT, Pedro; BEZERRA, Juliana; RAMASSOTE, Rodrigo. Educação Patrimonial: histórico, conceitos. Brasília, DF: Iphan/DAF/Cogedip/Ceduc, 2014.

FREIRE, Paulo; SHOR, Ira. Medo e ousadia: o cotidiano do professor. 1. ed. Rio de Janeiro: Paz e Terra,1986. PDF. Disponível em: 
http://www.gestaoescolar.diaadia.pr.gov.br/arquivos/File/otp/livros/medo_ousadia.pdf. Acesso em: 10 jul. 2021.

FREIRE, Paulo. Pedagogia do oprimido, 17ª . ed. Rio de Janeiro: Paz e Terra, 1987.

FREIRE, Paulo. Conscientização: teoria e prática da libertação: uma introdução ao pensamento de Paulo Freire. São Paulo: Cortez \& Moraes, 1979.

FUNARI, Pedro Paulo Abreu; FUNARI, Raquel dos Santos. Educação patrimonial: teoria e prática. In: André Luis Ramos Soares; Sérgio Célio Klamt. (Org.). Educação Patrimonial: teoria e prática. 1. ed. Santa Maria: Editora da UFMS, 2008, p. 11-21.

GARRAFFONI, Renata Senna. Cultura material greco-romana: algumas reflexões acerca do ensino e pesquisa de Arqueologia Clássica no Brasil. Romanitas Revista de Estudos Grecolatinos, v. 2, 2013, p. 219-230.

GONÇALVES, Janice. Patrimônio cultural: a educação em múltiplos sentidos. Patrimônio, ensino e educação: formação profissional. Porto Alegre, RS: Centro Histórico-Cultural Santa Casa, 1 ed., 2017, p.36-49.

HORTA, Maria de Lourdes Parreiras; GRUNBERG, Evelina; MONTEIRO, Adriane Queiroz. Guia básico de educação patrimonial. Petrópolis: Museu Imperial/IPHAN/MinC, 1999.

MAGALHÃES, Leandro Henrique; ZANON, Elisa Roberta; BRANCO, Patrícia Martins Castelo. Educação Patrimonial: da teoria à prática.1. ed.- PR: UNIFIL, v.1. 2009.

PELEGRINI, Sandra de Cássia Araújo; FUNARI, Pedro Paulo Abreu. O que é patrimônio cultural imaterial. São Paulo. Brasiliense, 2006.

SCHWENGBER, Jackson; SILVA, Diego Scherer da; TRINDADE, Rhuan Zaleski. Fontes históricas, patrimônio imaterial e ensino de história. Aedos: Revista do Corpo Discente do Programa de Pós-Graduação em História da UFRGS (Online), v. 11,2012, p. 456-469.

SCIFONI, Simone. Educação e patrimônio cultural: reflexões sobre o tema. Educação

Patrimonial: Reflexões e práticas. João Pessoa: Superintendência do IPHAN na Paraíba. 1. ed., v. 1, 2012, p.30-37.

SCIFONI, Simone. Para repensar a educação patrimonial. Cadernos do Patrimônio Cultural: educação patrimonial. Fortaleza: IPHAN, 2015, p. 195-205.

SILVEIRA, Flávio Leonel Abreu da.; BEZARRA, Márcia. Educação patrimonial: perspectivas e dilemas. In: ECKERT, Cornelia; LIMA FILHO, Manuel Ferreira.; BELTRÃO, Jane Felipe. (Org.).

Antropologia e Patrimônio Cultural: diálogos e desafios contemporâneos. 1. ed. Florianópolis: Nova Letra/ABA/Fundação Ford, 2007, p. 11-21.

THOMPSON, Analucia; et al. Dicionário Iphan de Patrimônio Cultural. 1. ed. Rio de Janeiro/Brasília: Iphan, 2015. 